\title{
Vertikal Kawasan Central Business District di Surabaya
}

\author{
Indah Nuer Sistyaningsih dan Rika Kisnarini \\ Departemen Arsitektur, Fakultas Teknik Sipil dan Perencanaan, Institut Teknologi Sepuluh Nopember (ITS) \\ e-mail: rika@arch.its.ac.id
}

\begin{abstract}
Abstrak-Perkembangan Central Business District di kota Surabaya diikuti dengan meningkatnya jumlah permukiman berupa kampung kota yang diisi masyarakat berpenghasilan rendah dengan kondisi fisik kurang baik, kepadatan tinggi, dan ketersediaan sarana umum yang minim. Keberadaannya dianggap memberi pengaruh negatif bagi perkembangan kawasan bisnis dan rentan terhadap isu penggusuran. Sedangkan masyarakat rata-rata tidak mau berpindah ke rumah susun karena dianggap mengaburkan sifat-sifat masyarakat kampung. Hal ini yang melatarbelakangi perlu adanya pembangunan hunian vertikal dengan pendekatan perilaku masyarakat kampung guna meningkatkan kualitas hidup dan memperbaiki wajah perkotaan dengan mengangkat potensipotensi kampung kota yang berada dekat dengan kawasan pusat bisnis di Surabaya.
\end{abstract}

Kata Kunci-Central Business District, Kampung, Urban.

\section{PENDAHULUAN}

$\mathrm{K}^{\circ}$ OTA Surabaya menunjukkan bahwa banyak permukiman yang dihasilkan dari embrio kampung yang masih tersisa pada kawasan-kawasan tertentu dengan sebutan Kampung Jawa, Kampung Madura, Kampung Arab, Kampung Cina dan sebagainya. Salah satu kawasan dengan pemukiman yang masih bertahan ditengah perkembangan Kota Surabaya sebagai Central Business District (CBD) adalah di kawasan Urip Sumoharjo karena dekat dengan daerah Tunjungan yang terkenal di Surabaya.

Banyak kampung-kampung kota di kawasan ini berupa permukiman legal yang tertata atas peran pemerintah yang mengajak dan mengembangkan kemampuan warganya untuk bisa melakukan penataan pada kampungnya. Karakter yang tampak pada warga di perkampungan adalah homogenitas dan nilai kebersamaan yang lebih kental karena telah lama tinggal berkelompok pada wilayah yang sama. Sehingga banyak kampung tertata karena kerjasama warganya. Banyak pula kampung yang sangat potensial untuk mendukung aktifitas kota secara keseluruhan. Oleh karena itu keberadaannya perlu dipertahankan demi mendukung aktifitas ekonomi di sekitarnya [1].

Namun akibat dari daya tarik kawasan ini penduduk datang dengan kenyataan akan keterbatasan ruang untuk hunian menimbulkan munculnya permukiman yang semakin padat dan potensi untuk menjadi kumuh. Bukan hanya padat penduduk tetapi juga padat bangunan karena pemanfaatan lahan yang sangat tinggi, sehingga selain akses jalan semua permukaan lahan telah tertutup oleh dasar bangunan hampir 90\%. Hal ini tidak sesuai dengan ketentuan 30\% kawasan yang seharusnya menjadi ruang terbuka hijau [2].
Masalah permukiman akan semakin pelik, karena begitu banyaknya faktor-faktor yang saling berkaitan tumpang tindih didalamnya. Permukiman sebagai wadah kehidupan manusia bukan hanya menyangkut aspek fisik dan teknis saja, tetapi juga aspek sosial, ekonomi, dan budaya dari para penghuninya. Kampung - kampung di kawasan ini Urip Sumoharjo tidak bisa begitu saja dihilangkan. Karena sudah lama ada dan sangat membantu para pekerja di area CBD dalam penyediaan hunian murah. Kampung - kampung ini juga telah menjadi identitas permukiman di Surabaya.

Seharusnya dengan adanya pengembangan kawasan CBD, kampung disekitarnya juga bisa diikutsertakan kedalamnya. Bisa dengan adanya kegiatan wisata yang menawarkan kampung dengan budaya lokal atau juga dengan mengembangkan kegiatan sektor ekonomi informal yang berlangsung didalamnya dan selaras dengan sekitarnya sesuai dengan potensi lokasi kawasan yang strategis sehingga kampung ini bisa menjadi kampung mandiri.

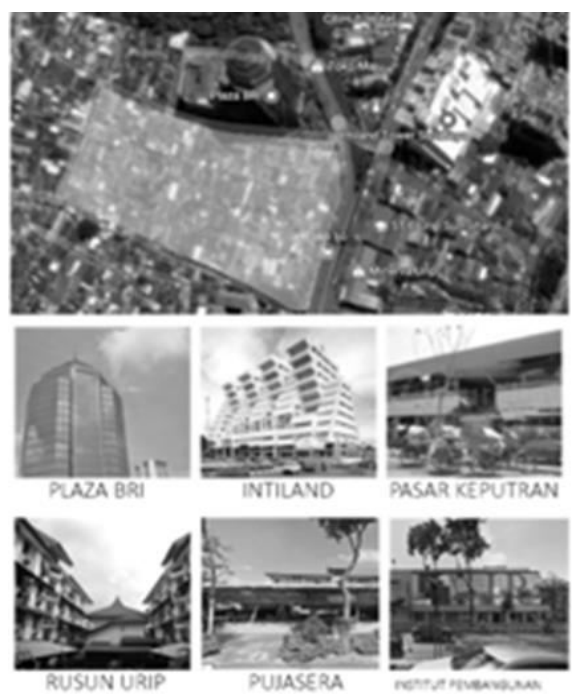

Gambar 1. Lokasi kampung kota di kawasan Urip Sumoharjo yang dikelilingi bangunan pusat bisnis di Surabaya.

\section{EKSPLORASI DAN PROSES RANCANG}

Pendekatan yang digunakan adalah pendekatan intrinsik, yaitu Cybernetics menurut Forster dalam buku Arsitektur dan Perilaku Manusia (2004) menekankan perlunya mempertimbangkan kualitas lingkungan yang dihayati oleh pengguna dan pengaruhnya bagi pengguna lingkungan tersebut. Dengan mengaitkan berbagai fenomena yang mempengaruhi hubungan antara manusia dan lingkungannya, termasuk lingkungan fisik dan sosial. Desain lingkungan 
Cybernetics ini dapat menjadi wahana untuk mengubah dampak negatif dari kawasan yang berwawasan sempit, menjadi lingkungan yang dapat mempunyai kualitas sebagai ruang tempat berhuni yang nyaman [3].

Pendekatan Arsitektur Perilaku didasarkan pada pemikiran bahwa kebutuhan keluarga akan ruang menjadi jelas bila dilacak dari kegiatan-kegiatan serta cara penggunaan ruang sehari-hari. Kebutuhan ruang yang sesungguhnya dapat ditemukan melalui penyediaan ruang untuk aktivitas mereka. Memperbaiki adaptabilitas berarti memperpanjang fungsionalitas apartemen melalui kapabilitas ruang untuk merubah (a) fungsi ruang yang ada, dan (b) dimensi ruang baik secara vertikal maupun horisontal, serta kemampuan keluarga dalam mengadaptasikan kebutuhan mereka terhadap ruang yang tersedia [4].

Tujuan mempelajari pola perilaku adalah untuk mengetahui lingkungan yang harus dipenuhi, yaitu dengan mengetahui bagaimana pribadi yang berbeda beraksi berbeda pula terhadap lingkungan yang beragam, bagaimana kombinasi tertentu antara individu dan settingnya berinteraksi menghasilkan berbagai pola perilaku tertentu dan dapat menghubungkan lingkungan fisik dengan manusia sebagai pengguna dan kebutuhannya secara lebih tepat atau lebih sesuai.

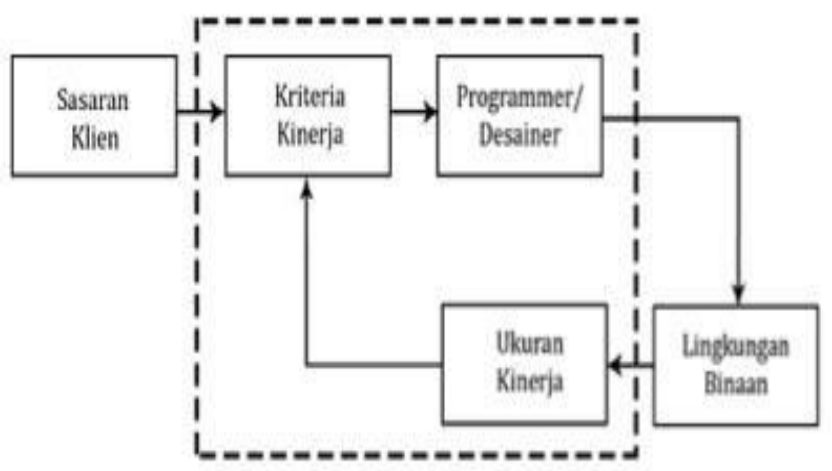

Gambar 2. Proses rancangan pada pendekatan cybernetics (Sumber: Arsitektur dan Perilaku Manusia, 2004).

Mengikuti metode desain dari Design Process and Practice-Richard Buchannan (1997). Proses pencarian isu dan pengumpulan data berada didalam tujuan dan strategi yang digunakan atau produk desain apa yang dimunculkan, lalu dalam mendesain objek harus mendapat uraian berupa analisaanalisa dari pendekatan Arsitektur Perilaku dan permasalahan yang ada. Selanjutnya perlu adanya penetuan konsep-konsep yang desain yang sesuai dengan pendekatan sehingga konsep ini dapat menjadi desain arsitektur yang sesuai dalam penyelesaian isu yang ada [5].

Arsitektur Perilaku digunakan karena berkaitan dengan cara berhuni warga di kampung serta memaksimalkan potensinya dengan memberikan fasilitas yang mendukung kegiatan warga di kawasan CBD. Selain itu perlu adanya desain ruang hunian yang memungkinkan pengguna untuk beradaptasi, memasukkan kebutuhan spasial kedalam ruang dan akses untuk mengubah desain ruang dalam.

\section{HASIL RANCANGAN}

Konsep Adaptasi yang dirasa cocok untuk hal ini menurut Moffat dan Russell (2001) konsep Adaptasi dapat dipecah menjadi beberapa strategi sederhana, yaitu:

1. Fleksibilitas atau memungkinkan pergeseran kecil dalam perencanaan ruang

2. Konvertibilitas atau memungkinkan untuk perubahan penggunaan bangunan

3. Ekspansi atau memfasilitasi penambahan jumlah ruang dalam sebuah bangunan [6].

Sehingga muncul modul $4 \times 4$ meter $^{2}$ yang dirasa paling cocok dan sederhana dalam memenuhi kebutuhan penghuni. Nantinya jumlah modul akan menyesuaikan jumlah anggota keluarga dan tetap dapat melakukan ekspansi. Dalam hal ini modul unit hunian dibuat open plan agar penghuni bisa mengatur sendiri kebutuhan ruangnya dan bisa menambah ruangnya dengan memberikan peluang untuk berkembang.

Pada dasarnya konsep ruang bersama milik warga kampung berupa ruang yang terbentuk dari deretan rumah-rumah yang membentuk hurus "U". Ruang ini fungsi utamanya sebagai akses jalan namun biasa juga digunakan untuk parkir kendaraan, tempat bermain anak, dan tempat bekumpul. Oleh karena itu pada desain, penataan modul dibuat saling berhadapan membentuk huruf " $U$ " sehingga bagian tengah akan membentuk ruang yang dimaksudkan untuk ruang bersama dan ruang terbuka hijau ditiap unit blok hunian.

Fasad bangunan juga dibuat sederhana dengan batu bata ekspos yang nantinya bisa beradaptasi sesuai kemampuan penghuni dalam mengubah tampilan tiap hunian mereka sehingga tampak keberagaman yang khas dalam konsep kampung. Atap hunian juga dibuat sederhana berupa atap pelana. Untuk bagian balkon yang difungsikan untuk jemuran karena menghadap keluar maka perlu adanya privasi agar terlihat lebih rapi dari tampak luar. Perforated metal digunakan sebagai penutup agar angin dan cahaya matahari dapat tetap. Karena konsep hunian modular, sistem stuktur yang digunakan adalah rigid frame dari beton dengan ukuran $4 \times 4$.

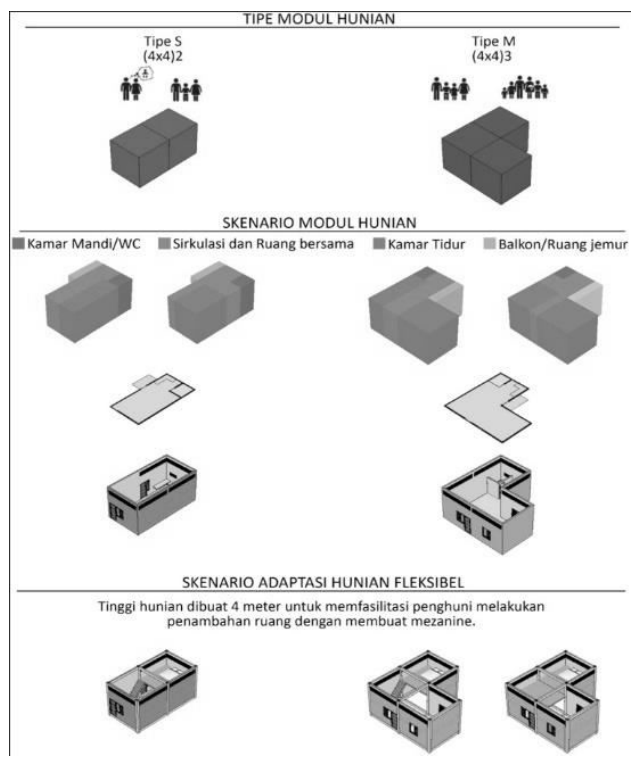

Gambar 3. Konsep Unit Hunian. 


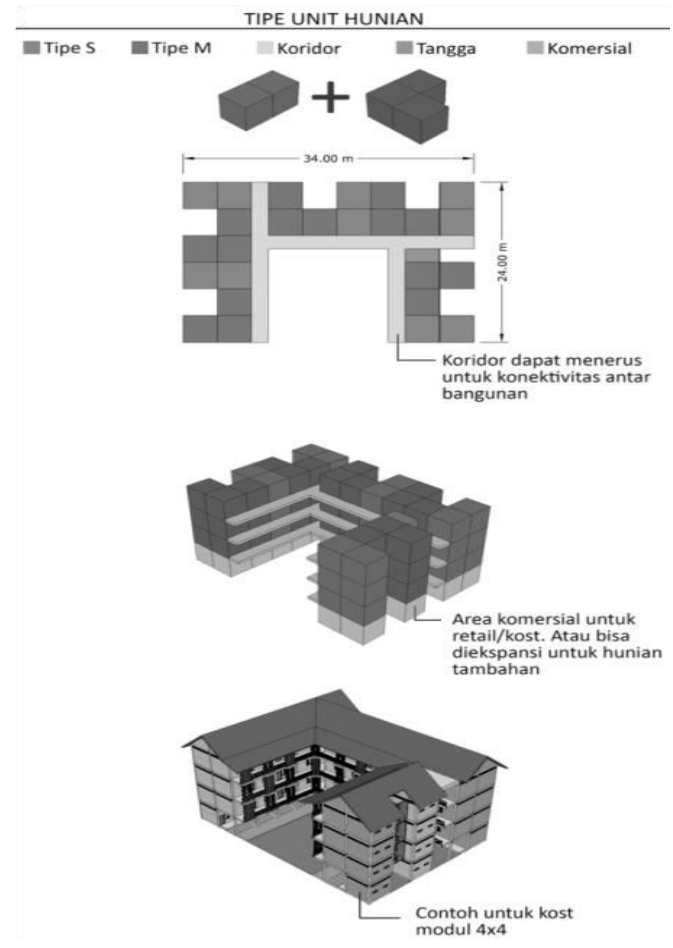

Gambar 4. Konsep Blok Hunian.

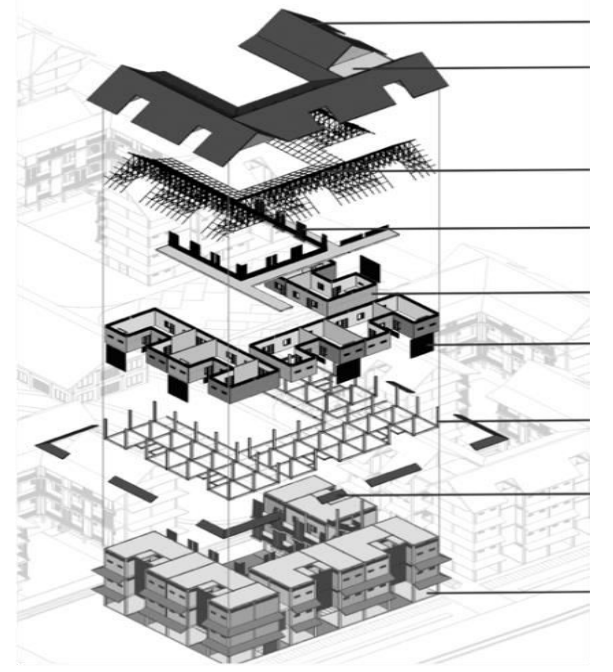

Gambar 5. Aksonometri sistem struktur bangunan dan fasad.

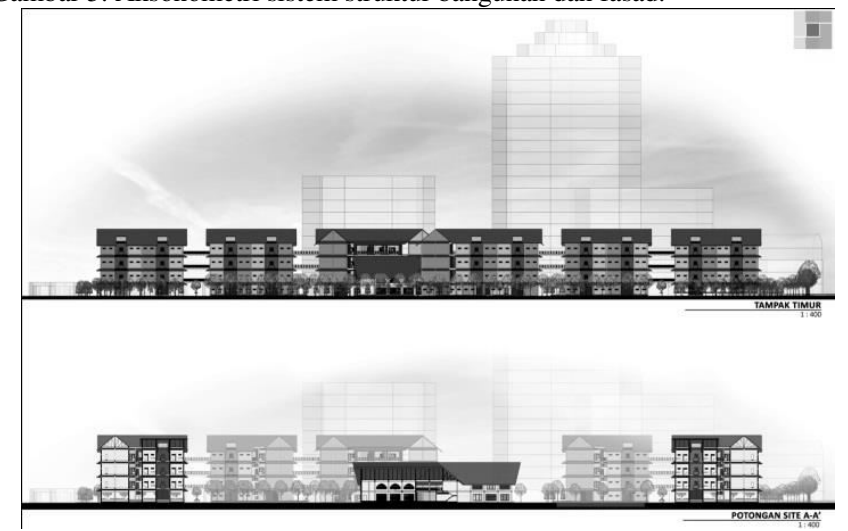

Gambar 6. Tampak dan Potongan yang memperlihatkan blok bangunan saling terhubung dengan jembatan pada bagian koridornya.

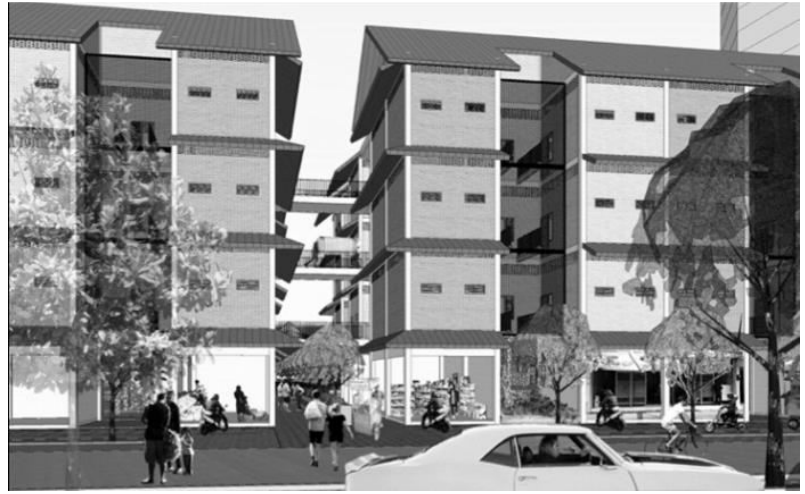

Gambar 7. Suasana area komersial kampung vertikal dan tampak unit bangunan yang saling terhubung.

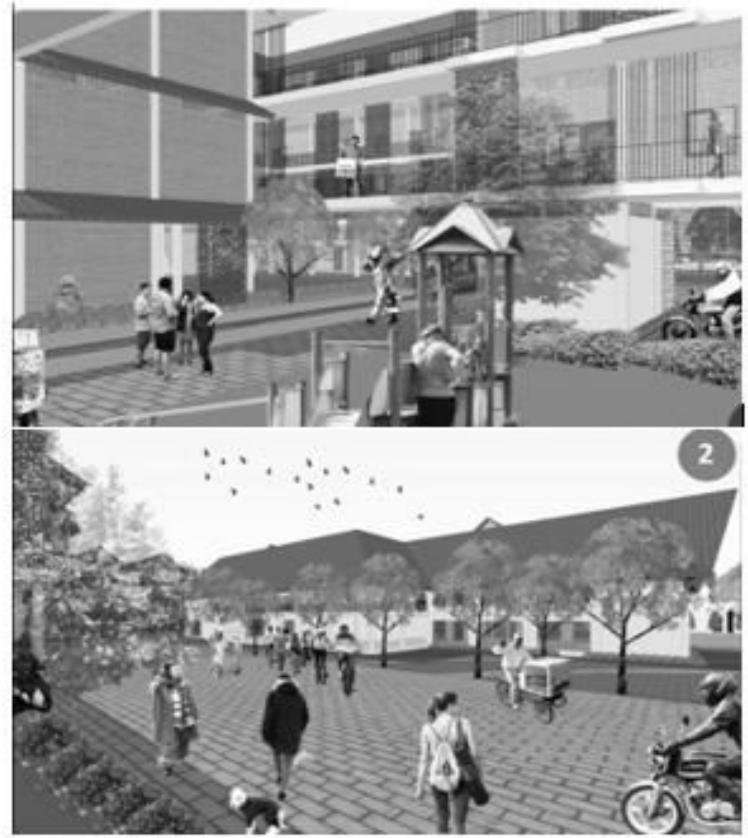

Gambar 8. Suasana ruang komunal penghuni kampung vertikal dan ruang terbuka hijau. Area ini bisa diakses masyarakat luar.

Tiap blok bangunan juga saling terhubung melalui koridor sebagai konsep dari sirkulasi pada kampung yang berupa gang-gang sebagai jalan utama dan ruang bersama.

\section{KESIMPULAN/RINGKASAN}

Kampung vertikal kawasan Central Business District merupakan sebuah objek arsitektural yang merespon isu kepadatan penduduk dan bangunan pada kampung - kampung yang memiliki potensi karena berada di pusat kota. Dengan pendekatan Arsitektur Perilaku, kampung vertikal mengadaptasi cara menghuni warga kampung dengan pemetaan ruang-ruang serta sirkulasi berupa gang, juga pemanfaatan ruang bersama antar tetangga serta kegiatan ekonomi informal.

Kampung vertikal yang adaptable dibuat modular agar memudahkan penghuni dalam mengembangkan fungsi-fungsi ruang yang ada didalamnya menyesuaikan waktu dan kebutuhan. Desain ini mampu memberikan ruang-ruang baru 
seperti ruang terbuka hijau yang sebelumnya tidak ada, untuk menciptakan lingkungan hidup yang lebih baik. serta ruang untuk memanfaatkan keberadaan kampung ditengah kota dalam memberikan kebutuhan masyarakat diluar kampung vertikal ini seperti area komersial, kost-kostan dan ruang publik.

Dengan menghadirkan objek desain dari material, fasad, dan tampak bangunan yang sederhana dan beragam menyesuaikan karakteristik kampung serta memberikan hunian yang adaptable bagi penghuninya dan tetap memberikan manfaat untuk lingkungan sekitar. desain ini dirasa mampu untuk menjawab permasalahan bagaimana hunian vertikal yang sederhana namun nyaman untuk masyarakat dengan konsep kampung dapat meningkatkan potensi kampung kota di Surabaya.

\section{DAFTAR PUSTAKA}

[1] J. Silas, "The Kampungs of Surabaya, Municipal Goverment of Surabaya," Surabaya, 1988.

[2] Anonymous, "RTRW Kota Surabaya 2013 - 2034," 2016. [Online]. Available: http://jdih.surabaya.go.id/pdfdoc/perda_731.pdf.

[3] Laurens and J. Marcella, Arsitektur dan Perilaku Manusia. Jakarta: Grasindo, 2004.

[4] R. Kisnarini, Functionality and Adaptability of Low Cost Apartment Space Design. A case of Surabaya Indonesia. Surabaya: ITS Press, 2015.

[5] H. Dubberly, How do you design? San Fransisco: Dubberly Design Office, 2004.

[6] P. Russell and S. Moffatt, "Assessing buildings for adaptability: EnergyRelated Environmental Impact of Buildings," IEA Annex, vol. 31, no. 2, 2001. 